University of Nebraska - Lincoln

DigitalCommons@University of Nebraska - Lincoln

Faculty Publications in the Biological Sciences

Papers in the Biological Sciences

2009

\title{
Macroevolutionary Tests of Pollination Syndromes: A Reply to Fenster et al.
}

Stacey DeWitt Smith

University of Nebraska - Lincoln, ssmith19@unl.edu

Cécile Ané

University of Wisconsin, Madison, ane@stat.wisc.edu

David A. Baum

University of Wisconsin - Madison, dbaum@wisc.edu

Follow this and additional works at: https://digitalcommons.unl.edu/bioscifacpub

Part of the Life Sciences Commons

Smith, Stacey DeWitt; Ané, Cécile; and Baum, David A., "Macroevolutionary Tests of Pollination Syndromes: A Reply to Fenster et al." (2009). Faculty Publications in the Biological Sciences. 114. https://digitalcommons.unl.edu/bioscifacpub/114

This Article is brought to you for free and open access by the Papers in the Biological Sciences at DigitalCommons@University of Nebraska - Lincoln. It has been accepted for inclusion in Faculty Publications in the Biological Sciences by an authorized administrator of DigitalCommons@University of Nebraska - Lincoln. 


\title{
Macroevolutionary Tests of Pollination Syndromes: A Reply to Fenster et al.
}

\author{
Stacey DeWitt Smith,' Cécile Ané, ${ }^{2}$ and David A. Baum '
}

\author{
' Department of Botany, University of Wisconsin, Madison, Wisconsin, USA \\ 2 Department of Statistics, University of Wisconsin, Madison, Wisconsin, USA \\ S. D. Smith, current affiliation: School of Biological Sciences, University of Nebraska-Lincoln, Lincoln, Nebraska, USA \\ E-mail addresses of the authors: ssmith19@unl.edu , ane@stat.wisc.edu , dbaum@wisc.edu
}

\begin{abstract}
Studies of floral ecology and evolution are often centered on the idea that particular floral trait combinations, or syndromes, represent adaptations for particular pollinators. Despite the conceptual importance of pollination syndromes, few macroevolutionary studies have statistically examined the relationship between pollinators and floral traits. Using 15 species of lochroma, Smith et al. applied phylogenetically structured correlation analyses to test the relationship between floral variation and pollination system, quantified in terms of the importance of major pollinator groups. This study revealed that pollinator shifts are tied to changes in nectar reward and floral display but are not significantly correlated with changes in corolla length or color, contrary to what might be predicted from classical pollination syndromes. Fenster et al. question these findings because our pollinator importance estimates included recently introduced honey bees. To address this concern, we recalculated importance values excluding honey bees and repeated the analyses. We found the same patterns as in our original study with significant correlations between pollinators and nectar reward and display. We conclude that phylogenetic approaches provide essential tools for testing macroevolutionary predictions of pollination syndromes and, by applying these approaches to other radiations, we can refine our understanding of the role of pollinators in floral diversification.
\end{abstract}

Pollination syndromes are combinations of floral traits that have arisen many times independently across flowering plants and are thought to reflect adaptation for particular pollinators (Faegri and van der Pijl 1966; Stebbins 1970; Fenster et al. 2004). This idea of a close correspondence between flower types and pollination mode has had a major impact on research in plant ecology and evolution. Floral traits comprising syndromes have been targeted in studies of phenotypic variation and selection (e.g., Johnston 1991; Schueller 2007), and quantitative and molecular genetic studies have begun to identify the loci that underlie differences in these traits (Bradshaw et al. 1998; Stuurman et al. 2004; Hobollah et al. 2007). Pollination syndromes are also used to categorize species and describe diversity in clades or communities (Cadotte and Lovett-Doust 2001; Beardsley et al. 2003; Roalson et al. 2003). Despite their broad influence, pollination syndromes have rarely been tested statistically on a macroevolutionary scale using phylogenetic comparative methods (but see Armbruster 1996, 2002). Although Fenster et al. (2009) agree that phylogenetic approaches offer a powerful complement to other studies of pollination syndromes, they raise objections to the approach and conclusions we presented in Smith et al. (2008a). 
Our study aimed to test a key prediction of pollination syndromes, that shifts in pollination system are correlated with changes in floral traits. Taking a phylogenetic approach, we studied the pollination ecology and floral trait variation in a core group of Iochrominae, a clade of Andean shrubs in the Solanaceae. By sampling nearly all the species within this core clade, we sought to determine the extent to which pollinator shifts could explain the observed floral variation. We chose to focus our analysis on four floral traits: flower length, nectar reward, display size, and flower color. Fenster et al. (2009) suggest that studying this limited set of floral traits prevented us from detecting pollination syndromes. We recognize that syndromes involve many aspects of floral morphology (Wilson et al. 2004) and that the four traits we have chosen are not likely to encompass of all the variation that influences plant-pollinator interactions. Nonetheless, the traits we selected are all important components of syndromes and collectively account for most of the floral diversity in Iochroma. Other characters such as nectar guides or style exsertion that are included in some pollination syndromes, are largely invariant in Iochroma.

In terms of characterizing pollination system, we chose to use the continuous variable, pollinator importance, which takes into account both visitation and pollen deposition. Importance was calculated separately for four major groups of pollinators (hummingbirds, Hymenoptera, Lepidoptera, and Diptera) and was directly compared to the continuous floral trait variables using single (pairwise) and multiple phylogenetic correlation analyses. Fenster et al. (2009) suggest that instead of considering pollination as a continuous variable, the species should have been grouped into discrete categories based on whichever pollinator group accounted for most (>75\%) of their pollination. Although we find such categorization useful for discussion (Smith et al. 2008b), we consider the continuous variable preferable for quantitative analyses. Pollination systems range from more to less generalized (Waser et al. 1996), and we see no reason to assume that a single "dominant" pollinator that provides $75 \%$ or more of the fertilization for a particular species is uniquely effective in influencing the selective regime. Additionally, whatever statistical power one might have to detect a real correlation is likely to be reduced by converting continuous measures into discrete alternative states. For both these reasons, we consider it preferable to use a quantitative estimate over a rather arbitrary assignment of species to pollination system.

Fenster et al. (2009) point out that the honey bee Apis mellifera, a common pollinator of Iochroma species, was introduced relatively recently to the Americas, and they suggest that it should not have been included in our pollinator importance estimates. Although the composition of pollinator faunas fluctuates naturally over time (Herrera 1988), we agree that dealing with recently introduced species presents a challenge for these sorts of comparative ecological studies. In the case of honey bees, it is impossible to know how their arrival might have changed the pollination system of native plants (reviewed in Goulson 2003). If the honey bees had displaced nonhymenopteran pollinators, then it would seem appropriate to remove them from the analyses. However, if they displaced or outcompeted native bees as pollinators of Iochroma, then pollinator importance values including the honey bees would provide the best estimate of the importance of Hymenoptera prior to the arrival of honey bees.

To determine the potential effect of including honey bees in our comparative analyses, we recalculated the importance values with the honey bees omitted and reran the single correlation analyses. Because we used relative importance values for each pollinator group, changing the importance of hymenoptera by removing honey bees changes the relative importance of other groups of pollinators (Table S1). Although Fenster et al. (2009) correctly recalculated hummingbird importance after removing bees, they did not recalculate the importance of the other groups (Hymenoptera, Lepidoptera, and Diptera) nor did they examine how the adjusted values would affect the correlations with floral traits. Using the importance values excluding honey bees, we reran correlation analyses for all four groups of pollinators. Comparing with Table 3 in Smith et al. (2008a), we found that the exclusion of honey bees had little quantitative effect and resulted in no change in terms of significant correlations (Table S2). As in Smith et al. (2008a), reward and display were significantly positively correlated with hummingbird importance and negatively correlated with dipteran importance. Hymenopteran importance was again positively correlated with display, and lepidopteran importance was negatively correlated with reward. All other correlations were nonsignificant. Thus, contrary to the inference of Fenster et al. (2009), the inclusion or exclusion of honey bees has no effect on our conclusions.

Fenster et al. (2009) note that in our paper, we discussed each of the four floral traits separately, and argue that we should consider the evolution of the flower as a complex, multivariate structure. We fully agree that the evolution of floral traits should be approached using multivariate statistical methods. Indeed, we included these methods in our paper (Smith et al. 2008a, table 4), making our study one of the very few to develop and implement multivariate, phylogenetically structured analyses (see also Ives et al. 2007, Lavin et al. 2008). We pursued multivariate analyses specifically to determine which suites of floral traits were evolving jointly with pollination systems. These analyses indicated that nectar reward and display evolve in a correlated fashion with pollination system, whereas flower color and corolla length evolve largely independently of changes in pollination system. Our interpretation of these results is that reward and display are components of the suite of traits that respond to shifts between pollinator types in Iochroma. In contrast, the lack of correlation between pollinator shifts and flower color and length suggests that these traits are shaped by other evolutionary forces. 

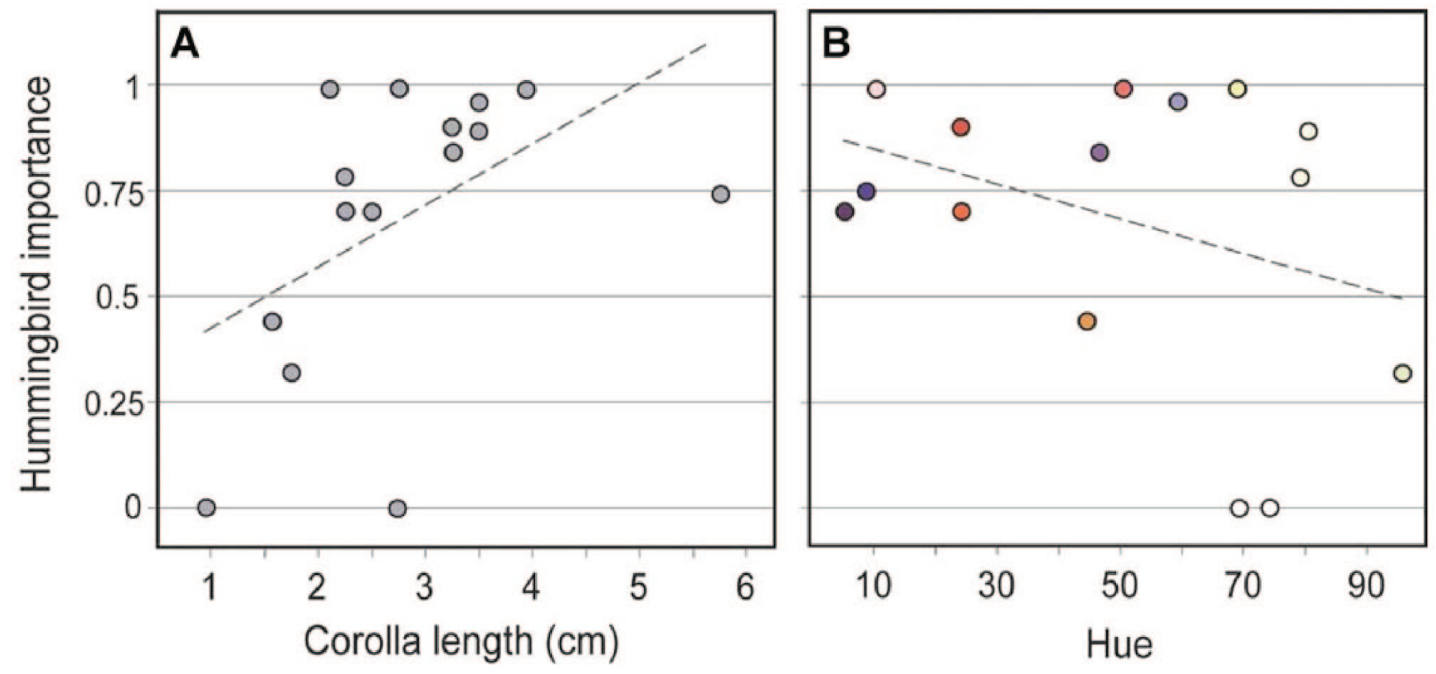

Figure 1. Hummingbird importance vs. corolla length and hue for 15 Iochroma species. Data from Smith et al. (2008a). Hue can be described as the type of color (e.g., red, blue). The dots representing each species in (B) are colored according to flower color by sampling the flower photographs in Smith et al. (2008a, Figure 1).

Fenster et al. (2009) argue that this observed lack of correlation does not necessarily contradict the pollination syndrome concept because the concept does not invoke a "universal correspondence" but rather a general tendency ( $p$. 10). For example, the presence of a large nectar reward may be considered part of the hummingbird syndrome even though some hummingbird-pollinated species do not produce large rewards. We agree that pollination syndromes predict general trends as opposed to a perfect correspondence between traits and pollinators, and our study was designed to test these predicted trends. We found significant relationships between pollinator shifts and nectar reward and display because they tend to evolve together across the phylogeny. Although the correspondence is not perfect, species with more bird pollination, for instance, tend to have larger nectar rewards and larger displays. Conversely, species with less bird pollination tend to have smaller rewards and smaller displays. Such strong patterns did not appear with flower color and corolla length.

In the case of corolla length, Fenster et al. (2009) suggest that the lack of a correlation might reflect different Iochroma species being pollinated by hummingbirds with different beak lengths. However, this cannot easily explain the observed pattern because many Iochroma species are pollinated by multiple hummingbird species with different beak lengths and conversely, several hummingbird species visit multiple Iochroma species with different corolla lengths (Smith et al. 2008b). Instead, considering the significant phylogenetic autocorrelation in corolla length, we suggested that the variation in tube length is explained not so much by current pollinator type but by a combination of phylogenetic inertia and other selective forces such as nectar-robbers. Although we cannot exclude the possibility that adding more taxa might elevate the nonsignificant cor- relation between pollinator shifts and corolla length (Figure 1A), it appears that this relationship is much weaker than those found with nectar reward and display.

Regarding flower color evolution in Iochroma, we found that the trait was highly labile across the phylogeny (as indicated by the low phylogenetic autocorrelation, Smith et al. 2008a) and that the frequent color shifts were not related to changes in the importance of any group of pollinators. Particularly striking was the variation of flower colors among the mostly hummingbird-pollinated taxa, which include white, blue, yellow, red, and purple-flowered species (Figure 1B). Fenster et al. (2009) state that these findings do not contrast with the predictions of pollination syndromes. However, flower color has been a central component of nearly every study describing pollination syndromes (e.g., Wilson et al. 2004; Whittall and Hodges 2007) and is often used as a predictor of pollination mode (Harrison 1999; Tripp and Manos 2008). Thus, the lack of a correlation between flower color and pollination system runs counter to at least some conceptions of pollination syndromes. That being said, we agree with Fenster et al. (2009) that the relationship between flower color and pollination system may vary across geographic regions (Grant 1966), and we consider this an interesting question for future study.

In conclusion, although it would certainly be desirable to increase the number of species studied so as to obtain more statistical power, we stand by our conclusion that two commonly cited elements of pollination syndromes, flower length and color, are not tightly linked to pollination mode in Iochroma. But it would be a mistake to extrapolate from this result to conclude that these traits are never correlated with pollination system. If one sets up the pollination syndrome concept not as a "19th century strawman" (Fenster et al. 2009) but as a set of testable phyloge- 
netic hypotheses, then we surely should expect cases in which particular traits are not shaped by pollination system in certain groups of plants. We do not imagine that future phylogenetic comparative studies will either prove or disprove the pollination syndrome concept in toto. Instead, we hope that, through multiple phylogenetic comparative studies, we will acquire a better understanding of which traits in which clades and communities are most tightly correlated with pollination system, and why.

\section{Acknowledgments}

SDS is supported by an NIH Ruth L. Kirschstein NRSA fellowship and the Center for Evolutionary Genomics at Duke University and the Duke Institute for Genome Sciences and Policy. The authors thank M. Burd and two anonymous reviewers for their helpful comments.

\section{Literature Cited}

Armbruster, W. S. 1996. Evolution of floral morphology and function: an integrated approach to adaptation, constraint, and compromise in Dalechampia (Euphorbiaceae). Pp. 241272 in D. Lloyd and S. Barrett, editors. Floral Biology. Chapman \& Hall, New York, NY.

Armbruster, W. S. 2002. Can indirect selection and genetic context contribute to trait diversification? A transitionprobability study of blossom-colour evolution in two genera. J. Evol. Biol. 15: 468-486.

Beardsley, P. M., A. Yen, and R. G. Olmstead. 2003. AFLP phylogeny of Mimulus section Erythranthe and the evolution of hummingbird pollination. Evolution 57: 1,397-1,410.

Bradshaw, H. D., Jr., K. G. Otto, B. E. Frewen, J. K. McKay, and D. W. Schemske. 1998. Quantitative trait loci affecting differences in floral morphology between two species of monkeyflower (Mimulus). Genetics 149: 367-382.

Cadotte, M. W., and J. Lovett-Doust. 2001. Ecological and taxonomic differences between native and introduced plants of southwestern Ontario. Ecoscience 8: 230-238.

Faegri, K., and L. Van Der Pijl. 1966. The Principles of Pollination Ecology. Pergamon Press, New York.

Fenster, C. B., W. S. Armbruster, P. Wilson, M. R. Dudash, and J. D. Thomson. 2004. Pollination syndromes and floral specialization. Ann. Rev. Ecol. Syst. 35: 375-403.

Fenster, C. B., S. Martén-Rodriguez, and D. Schemske. 2009. Pollination syndromes and the evolution of floral diversity in Iochroma (Solanaceae). Evolution, In press.

Goulson D. 2003. Effects of introduced bees on native ecosystems. Ann. Rev. Ecol. Evol. Syst. 34: 1-26.

Grant, K. A. 1966. A hypothesis concerning the prevalence of red coloration in California hummingbird flowers. Am. Nat. 100: 85-97.

Harrison, C. J., M. Moller, and Q. C. B. Cronk. 1999. Evolution and development of floral diversity in Streptocarpus and Saintpaulia. Ann. Bot. 84: 49-60.
Herrera, C. M. 1988. Variation in mutualisms: the spatio-temporal mosaic of a pollinator assemblage. Biol. J. Linn. Soc. 35: 95-126.

Hoballah, M. E., T. Gübitz, J. Stuurman, L. Broger, M. Barone, T. Mandel, A. Dell'Olivo, M. Arnold, and C. Kuhlemeier. 2007. Single gene-mediated shift in pollinator attraction in Petunia. The Plant Cell 19: 779-790.

Ives, A. R., P. E. Midford, and T. Garland Jr. 2007. Withinspecies variation and measurement error in phylogenetic comparative methods. Syst. Biol. 56: 252-270.

Johnston, M. O. 1991. Natural selection on floral traits in two species of Lobelia with different pollinators. Evolution 45: 1,468-1,479.

Lavin, S. R., W. H. Karasov, A. R. Ives, K. M. Middleton, and T. Garland Jr. 2008. Morphometrics of avian intestine, compared with non-flying mammals: a phylogenetic approach. Physiol. Biochem. Zool. 81: 526-550.

Roalson, E. H., L. E. Skog, and E. A. Zimmer. 2003. Phylogenetic relationships and the diversification of floral form in Achimenes (Gesneriaceae). Syst. Bot. 28: 593-608.

Schueller, S. 2007. Island-mainland difference in Nicotiana glauca (Solanaceae) corolla length: a product of pollinatormediated selection? Evol. Ecol.: 81-98.

Smith, S. D., C. Ané, and D. A. Baum. 2008a. The role of pollinator shifts in the floral diversification of Iochroma (Solanaceae). Evolution 62: 793-806.

Smith, S. D., S. J. Hall, P. R. Izquierdo, and D. A. Baum. 2008b. Comparative pollination biology of sympatric and allopatric Andean Iochroma (Solanaceae). Ann. Mo. Bot. Gard. 95: 600-617.

Stebbins, G. L. 1970. Adaptive radiation of reproductive characters in angiosperms I: pollination mechanisms. Ann. Rev. Ecol. Syst. 1: 307-326.

Stuurman, J., M. E. Hoballah, L. Broger, J. Moore, C. Basten, and C. Kuhlemeier. 2004. Dissection of floral pollination syndromes in Petunia. Genetics 168: 1,585-1,599.

Tripp, E. A., and P. S. Manos. 2008. Is floral specialization an evolutionary dead-end? Pollination system transitions in Ruellia (Acanthaceae). Evolution 62: 1,712-1,737.

Waser, N. M., L. Chittka, M. V. Price, N. M. Williams, and J. Ollerton. 1996. Generalization in pollination systems, and why it matters. Ecology 77: 1,043-1,060.

Whittall, J. B., and S. A. Hodges. 2007. Pollinator shifts drive increasingly long nectar spurs in columbine flowers. $\mathrm{Na}$ ture 447: 706-709.

Wilson, P., M. C. Castellanos, J. N. Hogue, J. D. Thomson, and W. S. Armbruster. 2004. A multivariate search for pollination syndromes among penstemons. Oikos 104: 345-361.

Supporting information follows. 
Supplementary Table 1. Pollinator imprtance values for hummingbirds, Hymenoptera, Lepidoptera and Diptera for 15 species of Iochroma. Values without honeybees were calculated as in Smith et al. 2008 (a,b); values including honeybees from Smith et al. (2008a,b) are shown for comparison.

\begin{tabular}{|c|c|c|c|c|c|c|c|c|}
\hline Species & $\begin{array}{l}\text { Hummingbird } \\
\text { importance } \\
\text { (with } \\
\text { honeybees) }\end{array}$ & $\begin{array}{l}\text { Hymenopteran } \\
\text { importance } \\
\text { (with } \\
\text { honeybees) }\end{array}$ & $\begin{array}{l}\text { Lepidopteran } \\
\text { importance } \\
\text { (with } \\
\text { honeybees) }\end{array}$ & $\begin{array}{l}\text { Dipteran } \\
\text { importance } \\
\text { (with } \\
\text { honeybees) }\end{array}$ & $\begin{array}{l}\text { Hummingbird } \\
\text { importance } \\
\text { (without } \\
\text { honeybees) }\end{array}$ & $\begin{array}{l}\text { Hymenopteran } \\
\text { importance } \\
\text { (without } \\
\text { honeybees) }\end{array}$ & $\begin{array}{l}\text { Lepidopteran } \\
\text { importance } \\
\text { (without } \\
\text { honeybees) }\end{array}$ & $\begin{array}{l}\text { Dipteran } \\
\text { importance } \\
\text { (without } \\
\text { honeybees) }\end{array}$ \\
\hline A. arborescens & 0 & 0.19 & 0.21 & 0.6 & 0 & 0.09 & 0.24 & 0.67 \\
\hline I. calycinum & 0.74 & 0.20 & 0 & 0.06 & 0.74 & 0.20 & 0 & 0.06 \\
\hline I. conferiflorum & 0.78 & 0.19 & 0.03 & 0 & 0.79 & 0.18 & 0.03 & 0 \\
\hline I. cyaneum & 0.84 & 0.14 & 0.02 & 0 & 0.84 & 0.14 & 0.02 & 0 \\
\hline I. edule & 0.99 & 0.01 & 0.01 & 0 & 0.99 & 0 & 0.02 & 0 \\
\hline I. ellipticum & 0 & 0.38 & 0.38 & 0.23 & 0 & 0.38 & 0.38 & 0.23 \\
\hline I. fuchsioides & 0.7 & 0.24 & 0.07 & 0 & 0.80 & 0.12 & 0.08 & 0 \\
\hline I. gesnerioides & 0.9 & 0.06 & 0.04 & 0 & 0.96 & 0 & 0.04 & 0 \\
\hline I.cf. peruvianum & 0.44 & 0.56 & 0 & 0 & 0.90 & 0.10 & 0 & 0 \\
\hline I.stenanthum & 0.99 & 0.01 & 0 & 0 & 1.00 & 0 & 0 & 0 \\
\hline I. umbellatum & 0.32 & 0.67 & 0.01 & 0 & 0.87 & 0.12 & 0.02 & 0 \\
\hline
\end{tabular}

Supplementary Table 2. Pairwise correlation coefficients for traits and pollinator groups calculated with data from (Smith et al. 2008a, b) excluding honeybees. As in Smith et al. 2008a, the pollinator importance variables were arcsin-square root transformed, reward per flower was square-root transformed, and display size and chroma were $\log _{10}$ transformed before analysis. For each pair of variables, the estimated correlation (corr) is given under the optimal value of $\alpha$ found inSmith et al. (2008a). For phylogenetically structured models $(\alpha<\infty)$, the mean across the 500 Bayesian tree sample is provided. Significant correlation coefficients $(p<0.05)$ are bolded.

\begin{tabular}{|c|c|c|c|c|c|c|c|}
\hline $\begin{array}{l}\text { Pollinator } \\
\text { Group }\end{array}$ & & $\begin{array}{l}\text { Corolla } \\
\text { length }\end{array}$ & Reward & Display & Chroma & Hue & Brightness \\
\hline Hummingbird & $\begin{array}{l}\text { Corr } \\
\alpha\end{array}$ & $\begin{array}{l}0.22 \\
\infty\end{array}$ & $\begin{array}{l}0.56 \\
\infty\end{array}$ & $\begin{array}{l}0.61 \\
100\end{array}$ & $\begin{array}{l}-0.06 \\
100\end{array}$ & $\begin{array}{l}-0.36 \\
\infty\end{array}$ & $\begin{array}{l}-0.36 \\
\infty\end{array}$ \\
\hline Hymenoptera & $\begin{array}{l}\text { Corr } \\
a\end{array}$ & $\begin{array}{l}0.15 \\
\infty\end{array}$ & $\begin{array}{l}-0.13 \\
\infty\end{array}$ & $\begin{array}{l}-0.57 \\
100\end{array}$ & $\begin{array}{l}0.11 \\
a\end{array}$ & $\begin{array}{l}0.37 \\
\infty\end{array}$ & $\begin{array}{l}-0.42 \\
\infty\end{array}$ \\
\hline Diptera & $\begin{array}{l}\text { Corr } \\
a\end{array}$ & $\begin{array}{l}-0.24 \\
\infty\end{array}$ & $\begin{array}{l}-0.57 \\
\infty\end{array}$ & $\begin{array}{l}-0.63 \\
\infty\end{array}$ & $\begin{array}{l}-0.10 \\
\infty\end{array}$ & $\begin{array}{l}0.19 \\
\infty\end{array}$ & $\begin{array}{l}0.15 \\
\infty\end{array}$ \\
\hline
\end{tabular}

